\title{
In peer review we trust-or do we?
}

Phil Wiffen

I recently enjoyed presenting a workshop on peer review at the European Association of Hospital Pharmacists Congress held in Barcelona. This reminded me of the importance of peer review on the one hand in terms of ensuring that papers published in this journal are reliable and engaging for readers but also the lack of science that underpins the peer review process and the inability to detect fraud or even mistakes.

By coincidence I came across a recent major research publication entitled 'Trust and Authority in Scholarly Communications in the Light of Digital Transition,

A number of interesting findings come through this report made up of an extensive literature review and some 3600 responses to an online survey. The responders were from across a wide range of scientific disciplines.

Some of the key findings include:

In terms of what people read, they want a top-tier author in a peer reviewed journal, available online at no personal cost. There was universal agreement that peer review is essential for maintaining quality and reliability.

In deciding where to publish, the quality and speed of peer refereeing was linked with perceived reputation of the journal and its impact factor. A highly targeted audience such as this journal is also valued.

The survey asked respondents about what was important to them. First the answer is that values have not changed in an era of digital publishing-the old values hold including the credibility of the data, and a well-formed argument. For many

Correspondence to Professor Phil Wiffen, Pain Research Unit, Churchill Hospital, Old Road, Oxford OX3 7LE, UK; phil.wiffen@nden.ox.ac.uk the abstract is extremely important-a salutary message as many of us leave this until the last minute!

Issues considered less important were country of affiliation, number of downloads and publisher.

Many researchers rely on their peers to tell them about research worth reading and they are relying more on Google Scholar, Google and also Wikipedia. Google Scholar is becoming a useful resource to find full text versions of difficult-to-obtain papers and has some useful metrics.

Peer review features highly in this report. Generally authors want to be published in peer review journals and they also feel secure in citing papers in such journals. Generally they see peer review as a positive experience which leads to an improvement in quality-even if the paper is rejected. They like the fact that publishers organise peer review though the reasons are not clear. Also they want blind reviewing so there is an opportunity to comment freely.

What they don't like includes the slow speed of the peer review process. At EJHP we try and keep things moving but that is not always easy. Recently we have examples where up to seven peer reviewers have been invited for a single paper and all have declined for one reason or another. Editors who are largely hands off are not popular and light touch peer review is not appreciated. Authors clearly want a good steer and also feedback they can learn from. They also dislike being misunderstood by reviewers (one of my pet hates) and being criticised by reviewers who display their ignorance in what they say. Finally in this section, conflicting reviewers' comments or recommendations were disliked. I am not sure what we can do about this and as an editor I try to give guidance to the author on how to deal with this scenario.

Given the rise of open access journals, there seems to be a generational split with older researchers being somewhat distrustful and younger ones seeing this type of publishing as attractive.

In spite of some acceptance, there were harsh comments on the recent proliferation of open access journals (often requiring a fee to publish). They were considered to be poor quality, a form of 'vanity publishing' for those wanting to boost their $\mathrm{CV}$ and considered to be poorly run and unprofessional.

Plagiarism was thought be rife though, as many publishers now scan for this including $B M J$ for this journal, the levels seem to be coming down. Citation behaviour was also discussed and inappropriate citation considered to be poor practice. This included inappropriate self-citation, citing the journal where the author wants to publish, citing papers mentioned by reviewers to increase the chance of acceptance.

So what is your view? Do you value peer review? If so I invite you to join our panel of reviewers to help improve the quality of what is published in EJHP. EJHP is now able to reward good reviewers with professional development points (CPD). So I guess I do trust in peer review and will do so until we have something that is proven to be better.

\section{Competing interests None.}

Provenance and peer review Commissioned; internally peer reviewed.

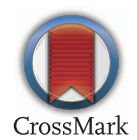

To cite Wiffen P. Eur J Hosp Pharm 2014;21:133.

Eur J Hosp Pharm 2014;21:133.

doi:10.1136/ejhpharm-2014-000473

\section{REFERENCE}

1 http://ciber-research.eu/download/20140115-Trust_ Final_Report.pdf 